\title{
CAPITAL, TRABALHO E INTELLIGENTSIA - MODERNIZAÇÃO E DESENVOLVIMENTO NO PENSAMENTO DE CELSO FuRTAdo
}

\author{
Vera Alves Cêpeda ${ }^{1}$
}

\begin{abstract}
Resumo: O objetivo deste trabalho é analisar alguns aspectos presentes no projeto furtadiano de desenvolvimento planejado que implicam numa contribuição única da obra desse autor para o pensamento social e político brasileiro. Pretendo destacar: 1) a implicação de sua teoria do subdesenvolvimento em direção ao status de uma teoria da modernização (teoria do desenvolvimento); e 2) diferenciar a proposta de desenvolvimento furtadiana do conjunto histórico do modelo desenvolvimentista das décadas de 50 e 60, destacando seu caráter inovador. Neste último ponto os elementos fundamentais são o peso da mudança institucional (papel da democracia) enquanto motor do desenvolvimento e a subversão dos lugares ocupados pela ação do capital e do trabalho na construção efetiva de um desenvolvimento global e consistente.

Palavras-chave: pensamento político brasileiro, desenvolvimento, democracia, modernização, intelligentsia.
\end{abstract}

Abstract - The objective of this study is to analyze some aspects in the design of development planned by furtado involving a single contribution of the work of this author to the Brazilian political and social thought. I want to stress: 1) the implications of his theory of underdevelopment toward the status of a theory of modernisation (theory of development), and 2) the proposal to differentiate proposed by furtado development of the whole history of the developmental model of the decades of 50 and 60, highlighting its innovative character. At this point the key elements are the weight of institutional change (paper democracy) as a driving force for development and subversion of seats occupied by the action of capital and labour in the construction of an effective global development and consistent.

Keywords: Brazilian political, thought, development, democracy, modernization, intelligentsia.

${ }^{1}$ Professora do departamento de Ciência Sociais da UFSCar. 
| 72 |

Capital, trabalho e intelligentsia...

\section{Introdução}

É impossível analisar o processo de constituição e transformação da sociedade brasileira sem discutirmos tanto o problema econômico quanto o fenômeno histórico do desenvolvimentismo e neste a contribuição lapidar da obra de Celso Furtado. No primeiro aspecto o indiscutível fato de nosso surgimento no horizonte das nações na moderna forma mercantil de colônia - termos nascido 'capitalistas' como afirma Caio Prado $\mathrm{Jr}$ - fez com que problemas referentes ao mundo da produção, da circulação e da acumulação orientassem e balizassem grande parte da arquitetura social, política e cultural do país. O próprio tempo histórico de nossa 'descoberta' como braço avançado das metrópoles européias na fase de expansão do mercantilismo já era expressão do espírito da modernidade e do movimento de racionalização que se cristalizaria depois no modelo de sociedade (divisão mecânica da solidariedade), da economia de mercado, na cultura racional (razão, trabalho e riqueza - tríade que compõe o ethos da modernidade como cálculo racional), na noção de indivíduo (e individualismo) e das diversas formas de contratualismo que ganhou melhor formato no modelo de Estado/ Nação. Este cenário é importante para destacar que no estudo da história nacional moderno e economia são duas faces de um mesmo problema. Até mesmo a definição de arcaico que se possa aplicar as características do Brasil Colônia ou Império, por exemplo, distanciam-se radicalmente do Ancien Régime presente no passado de outras nações. O paradigma da 'herança colonial - 'escravista, latifundiária, monocultora e mercantil-exportadora - origina-se, como afirmam Simonsen, Caio Prado Jr e Furtado, de uma adequação de nossa economia aos padrões internacionais gerando como corolário formas particulares de instituições e sociabilidade.

Hoje há praticamente um consenso sobre essa leitura, mas é resultado de um processo social razoavelmente recente e se consolida quando a dimensão econômica tornou-se o epicentro da vida nacional transformando-se também no leitmotif da vida intelectual. Esse encontro se deu com a questão do planejamento 
que emerge no debate brasileiro no início dos anos 40 e aparece sintetizado na teoria do subdesenvolvimento - talvez a mais vigorosa peça de artilharia intelectual sobre a formação histórica brasileira (pensando especificamente a elaboração proposta por Celso Furtado). Nela, cronologia, problemas institucionais, fases, estruturas sociais, conflitos e representações são articulados numa teoria totalizante capaz de explicar os momentos históricos como elos de uma cadeia dinâmica de eventos. A teoria do subdesenvolvimento é capaz, também, de estabelecer uma ponte entre a história mundial e o percurso da história nacional, anelando interno e externo e simultaneamente colocando a singularidade nacional como parte integrante no modelo orbital de uma modernidade heterogênea. No campo político, a teoria do subdesenvolvimento tornou-se uma proposta atraente e eficiente para se pensar o dilema da nação, substituindo temas anteriores como o "cadinho das raças", a debilidade institucional ou o atraso meramente político por uma teoria mais sofisticada e mais atualizada com os parâmetros em voga mundialmente ${ }^{2}$. A condição periférica associa-se com o paradigma da Revolução Burguesa: para sermos modernos é necessária a forma capitalista, urbano-industrial; para sermos modernos é necessário mudar a economia para alcançarmos uma estrutura social e política também moderna. Conceitos como etapismo ou dependência permitem enxergar racionalmente nosso atraso e também, procurar forma identicamente racionais de superação: ao invés de fardo, fase; ao invés de determinismo histórico, esforço da vontade política de transformação.

Dessa maneira a economia alcançou o privilegiado status analítico anteriormente exclusivo do ensaísmo político ou cultural e subverte a ordem dos fatores - a construção da nação passa por mudanças na estrutura econômica.

${ }^{2}$ É importante lembrar que a fase posterior aos anos 20 corresponde, no âmbito mundial, ao esfacelamento da hegemonia do pensamento liberal (no campo econômico e político) e a emergência de novas matrizes ou modelos societários como o comunismo, os fascismos, a social 
| 74 |

Capital, trabalho e intelligentsia...

A proposta de reflexão deste trabalho começa com o a emergência histórica da dobradinha conceitual subdesenvolvimento/ desenvolvimentismo, procurando ressaltar seu vínculo com a dimensão política. Uma ressalva importante sobre o desenvolvimentismo é que ele tem sido tratado na literatura nacional (quer nas abordagens produzidas pelas Ciências Sociais, pela Economia ou pela História) como um fenômeno histórico, como um conceito-síntese para uma época e sob essa homogeneidade conceitual deixando de lado a riqueza do processo histórico que o gerou. O problema é que sob a rubrica do subdesenvolvimento três pontos ficam obscurecidos: sua imbricação original na tese do subdesenvolvimento (produto cognitivo e teórico); sua conversão em estratégia ou técnica para promoção do desenvolvimento (campo da ação política) e a qualidade da finalidade que se propõe alcançar (projeto político-social, campo das ideologias, definição de que tipo de desenvolvimento deve ser alcançado).

Assim, adoto como ponto de partida investigativo a existência da heterogeneidade de temas, tratamentos, filiações e representação de interesses que se abrigaram no período sob o projeto histórico do desenvolvimento planejado e conduzido pelo Estado. Sabendo que este momento corresponde à um ponto de inflexão no rápido processo de modernização econômica que já vinha ocorrendo no país, fica fácil assimilar a implicação de que é nesse momento que se forma um novo compromisso social que se baseia na transformação da industrialização em questão nacional. Ao observamos o tema do desenvolvimentismo de uma maneira combinada é que fica mais nítida a compreensão do papel desempenhado pelas teses furtadianas nesse processo (e sua fácil conversão em pólo hegemônico no pensamento social brasileiro no período). A situação exponencial da obra de Furtado ampara-se na combinação feliz de três aspectos: o método,

democracia como respostas alternativas ao modelo excludente da Revolução Burguesa. 
o problema e a proposição. Descrito em vários estudos sobre o conjunto da obra desse autor o método se caracterizaria pela heterodoxia ou ecletismo intelectual: abordagem combinada de distintas dimensões sociais (economia, cultura, sociologia, história) e utilização de conceitos deslocados de várias correntes intelectuais (o estruturalismo marxista, a economia do lado da demanda e o regulacionismo keynesiano, a economia nacional de List, o papel das reformas institucionais, o historicismo). Olhado nesse ângulo as concepções furtadianas ficam fragilizadas porque aparentemente em nome de uma necessidade de compreender um objeto singular historicamente o autor recorresse a "estratagemas" que resultassem, ao final, numa perspectiva caleidoscópica da realidade. O centro dessa questão poderia ser o do improviso ou da excessiva criatividade teórica. Proponho ao contrário de uma leitura do método furtadiano como heteróclito na fina adesão de Furtado ao método da Sociologia do Conhecimento proposto por Karl Mannheim³.

A Sociologia do Conhecimento mannheineana sustenta-se tanto na leitura combinada e totalizante do social (autodenominada de método da Sociologia Sistemática) quanto na recepção de múltiplos focos de interpretação e explicações teóricas, aglutinadas no conceito de sintese intelectual. As tarefas da intelligentsia são de dois tipos para Mannheim. A primeira, de caráter epistemológico procura alcançar uma interpretação objetiva do mundo social, que só pode se dar pela concepção de que há pontos de interconexão de toda a vida societária no eixo histórico, revelados no pensamento social produzidos pelos distintos grupos em choque na sociedade. A segunda é o desafio da síntese uma vez que a multiplicidade dos enfoques (flexionados entre a Ideologia e a Utopia) é sempre parte

\footnotetext{
${ }^{3}$ Mesmo que Furtado não tenha explicitamente feito essa afirmação, há nos seus trabalhos recorrentes citações de Mannheim (especialmente nas obras autobiográficas); mais do que isso, se observarmos o processo de análise desenvolvidos nos textos de Furtado podemos detectar claramente o uso da Sociologia Sistemática e uma clara filiação à responsabilidade moral da intelligentsia - marca da tese mannheineana.
} 
| 76 |

Capital, trabalho e intelligentsia...

expressiva da realidade social (nem ilusão, nem mentira ou erro), devendo, então, serem condensados numa explicação unitária (Ideologia total).

Quanto ao problema e a proposição, estes aspectos podem explicar a enorme influência e importância do pensamento furtadiano, particularmente entre o final da década de 50 até o final dos anos $70^{4}$. O problema é o do atraso, base da interpretação de Furtado sobre a formação do Brasil e que configurou sua primeira grande contribuição intelectual na forma da teoria do subdesenvolvimento. Como uma interpretação do Brasil, a teoria do subdesenvolvimento foi capaz de estabelecer um sólido diálogo com a anterior tradição intelectual que tinha como objeto privilegiado de reflexão o problema da identidade nacional. Se 'para trás' a natureza da recepção da teoria do subdesenvolvimento foi promover uma história nacional, em seu momento coetâneo esta teoria teria força para avaliar o presente e possibilitar uma alternativa de futuro, ambas legitimadas por uma rigorosa análise de cunho teórico-econômico e por uma sofisticada interpretação sócio-histórica. É nesse desdobramento pragmático que a teoria do subdesenvolvimento vira projeto de desenvolvimento. Mas nessa metamorfose o problema é com o futuro e, portanto, não se trata mais do ser e sim do dever ser, abrindo a reflexão para o campo dos valores e o universo das proposições políticas. Este é o eixo da proposição e tendo essencialmente um caráter político torna-se uma exigência dos estudos voltados ao pensamento social qualificar o projeto de desenvolvimento furtadiano, ou seja, desvendar que tipo nação e de modernidade estavam em disputa quando Furtado produziu sua proposta. Por extensão,

\footnotetext{
${ }^{4}$ Os textos que servem de base para este artigo são os produzidos no período mais pujante das discussões desenvolvimentistas (perfazem aquele grupo de obras que em outro trabalho denominei de 'fase otimista' da produção furtadiana) Formação Econômica do Brasil (1959), Perspectiva da Economia Brasileira (DASP, 1958), A pré-revolução brasileira (Fundo de Cultura, 1962), Dialética do Desenvolvimento (Fundo de Cultura, 1964) e Teoria e Política do Desenvolvimento Econômico (Fundo de Cultura , 1967).
} 
clareando a proposição furtadiana também ficam visível quais os outros projetos (e o que representavam) na disputa do período.

\section{Entre o subdesenvolvimento e o projeto desenvolvimentista}

Anteriormente foi salientado que o subdesenvolvimento é parte processual na intelligentsia brasileira, produto de nossa evolução histórica, e, portanto, é datado e se corresponde a mudanças reais na estrutura social também possui uma paternidade cognitiva. A emergência do tema (e da teoria) do subdesenvolvimento tem dois momentos distintos no debate intelectual brasileiro: a abordagem inicial do problema pode ser encontrada na seminal obra de Roberto Simonsen já na década de 1930 e sua lapidação teórica mais madura encontrada na tese furtadiana dos anos 50 . O problema do atraso ou da inferioridade da nação brasileira frente a outros exemplos mundiais mais bem resolvidos é traço constante que move a intelligentsia brasileira desde a segunda metade do século XIX. Porém, em discurso proferido nos debates da Constituinte de 1934, Simonsen firmaria de maneira inédita que "o Brasil é um país pobre, com uma população pobre" e que esta pobreza tem base material, originada no fato de que na economia nacional "o divisor é sempre maior que o quociente". Se a população era pobre (diferente da compreensão de que estar circunstancialmente depauperada) era porque o país era pobre, incapaz de elevar a renda per capita e nacional. O baixo poder aquisitivo, ao contrário do propalado, tinha origem na insuficiência geral da capacidade produtiva do país: era estrutural e derivada da fragilidade da economia primário-exportadora.

O problema do salário está indissoluvelmente ligado ao da produção. Todos ansiamos - patrões e empregados do Brasil - que aqui se estabeleça uma justa remuneração do trabalho, que todos possam viver a vida digna (...) mas se a retribuição do homem é fixada em grande parte pela própria produção; 
| 78 |

Capital, trabalho e intelligentsia...

se esta é de pequeno valor em relação ao volume de mão de obra disponível, como obter um elevado quociente se o divisor é fraco e o dividendo cresce continuadamente? O nosso grande mal, atingindo todas as classes, principalmente a dos trabalhadores, é a insuficiência de ganho ${ }^{5}$.

O atraso qualifica-se agora como debilidade da estrutura econômica, incapaz de produzir o mínimo para suprir as necessidades da comunidade nacional. E por mais que a agricultura seja pujante (o que não correspondia mais à verdade, principalmente depois das sucessivas quedas do preço do café) a carestia, o mal estar social são expressões cabais de que "se o café vai bem, tudo o mais vai mal". Em Simonsen encontramos uma primeira versão da lógica do subdesenvolvimento sob a denominação de sub-capitalismo, no qual os problemas de pobreza e pauperização da vida social surgem condicionados pela desigual divisão do trabalho internacional (nosso modelo mercantil exportador) e, por extensão, pela incapacidade de transitarmos - enquanto economia atrasada a situação plena da modernidade apenas alcançada no modelo de uma "civilização machinica" (modelo industrial) ${ }^{6}$. A afirmação de que a condição de economia primário-exportadora era a origem de nossa baixa capacidade produtiva permitiu questionar a legitimidade da tese das vantagens comparativas e a ordem aparentemente natural das trocas no comércio mundial. Se de maneira espontânea a economia "tendia" à vocação agrícola, sua incapacidade de gerar a "riqueza

\footnotetext{
5 Simonsen, 1940:14.

${ }^{6}$ Estes argumentos são desenvolvidos em As crises no Brasil (1930), As finanças e a indústria (1931), A indústria em face da economia nacional (1937), Evolução industrial do Brasil (1939), Níveis de vida e a economia nacional (1940), trabalhos onde Simonsen elabora as bases originais do tema subdesenvolvimento: a perspectiva da pobreza estrutural; a recusa da teoria das 'vantagens comparativas' e das virtudes do comércio internacional; a critica ao modelo agrário-exportador; a defesa da racionalização da economia; e a necessidade de construção de um projeto
} 
da nação" talvez apontasse para uma falácia ou equívoco dessa proposição $0^{7}$ :

O ritmo e a intensidade da crítica simonseana à economia natural, de molde liberal, acentua-se entre 1934 e 1948, sofisticando-se até a defesa inédita do planejamento econômico, mas ainda peca pelo caráter descritivo e denunciativo, sem uma leitura rigorosamente teórica que a sustente.

Ao contrário, Furtado foi responsável pela blindagem teórica do conceito de subdesenvolvimento. Sua análise (encontrada ao longo das inúmeras obras produzidas) incide sobre três aspectos importantes do fenômeno subdesenvolvimento: seu caráter histórico derivado de uma posição das nações na divisão internacional do trabalho (economias centrais e 3 tipos de economias satélites); o desvendamento de sua dinâmica de funcionamento com base numa lógica econômica da acumulação e concentração crescente de riqueza nas economias centrais; e, por último, numa análise tendencial dessa dinâmica em direção ao aumento das assimetrias inicialmente apontadas. Furtado avançou em sua tese no aprofundamento da ruptura com as categorias do liberalismo amparada numa consistente crítica teórica, e essa nova perspectiva econômica permitiu a conversão da teoria do subdesenvolvimento em projeto desenvolvimentista.

Examinemos o argumento. Como ruptura inicial com o paradigma liberal encontramos uma análise negativa da combinação do laissez-faire com a teoria das vantagens comparativas, capaz de engendrar novas formas de organização das economias nacionais, distintas do modelo final ou padrão

de desenvolvimento nacional (economia e sociedade) rumo ao desenvolvimento pleno da nação - todos ancorados na análise do pauperismo nacional.

7 “O café sobre o qual tem repousado todo o progresso do país já está em superprodução (...). É numa política industrial fundada em bases racionais adequadas as condições de nosso meio que teremos que ir buscar, principalmente, a produção de bens sociais" (Simonsen, 1931:247). 
$\mid 80$ |

Capital, trabalho e intelligentsia...

das economias desenvolvidas. Furtado assinala em Teoria e Política do Desenvolvimento Econômico que a expansão do capitalismo central em contato com as estruturas autóctones das sociedades coloniais produziu pelo menos dois grupos distintos e subtipos de economias: as desenvolvidas, as subdesenvolvidas (divididas em grau superior e inferior) e as pobres. Cada uma delas, emergindo do processo de transição pré-moderno e moderno (com exceção da última, o circulo de ferro da pobreza) geraria dinâmicas e configurações diferentes. A diferença das estruturas econômicas nacionais havia sido prevista no argumento liberal como etapa ou na expansão virtuosa da divisão do trabalho tecnologia - aumento do mercado (na tese smithiana) ou como especialização otimizada dos recursos produtivos (vantagens competitivas ricardianas). O que a teoria furtadiana do subdesenvolvimento coloca em xeque é essa interpretação: a inserção na economia mundial geraria estruturas sociais e políticas locais anacrônicas, que somadas a lógica de transferência e não de repartição dos frutos do progresso técnico estabeleceria um outro tipo de economia e de sociedade (diferente na forma e no conteúdo das economias centrais, mas necessária enquanto mecanismo de realização e drenagem da riqueza). O desenvolvimento capitalista aparece assim como desigual e combinado, e não pode mais oferecer uma única visão de progresso para todas as posições no amplo espectro das trocas mundiais.

Um segundo ponto, é que a intensificação das assimetrias e o aumento de drenagem de riqueza das economias reflexas em direção às economias centrais também desqualificaria o princípio axiomático das virtudes da competição e do equilíbrio final promovido pela mão invisível do mercado. Ao contrário a condição de subdesenvolvimento é a de "filho bastardo" da mão invisível e a permanência dessa lógica impediria o sonho de constituição da independência econômica e da autonomia nacional. Como alternativa Furtado (como os demais cepalinos), apontava a necessidade de planejamento artificial do desenvolvimento econômico. Longe da economia natural e espontaneamente 
ordenada surgem as estratégias da planificação e da regulação econômica ancoradas na concepção da queima de etapas (substituição da mão invisível pela racionalidade planificadora) e pela internalização da dinâmica econômica (via protecionismo e aumento do mercado interno). As duas estratégias afastam-se radicalmente dos postulados da economia clássica, fazendo emergir no cenário econômico a figura demonizada que anteriormente havia entronizado e legitimado o pensamento liberal - o absenteísmo do Estado.

Podemos fazer neste ponto um pequeno balanço do que apontei como um percurso entre subdesenvolvimento desenvolvimentismo e sua filiação essencial à recusa dos postulados liberais em especial na obra de Furtado sobre a formação brasileira e sua possibilidade de futuro: a história nacional é resultante da estrutura e da superestrutura institucional gerada pelo lugar de nossa economia na divisão internacional do trabalho; a herança colonial não é apenas um traço do passado, mas um peso no presente do período, e constitui um obstáculo para a finalização positiva da modernização nacional - inclusive para a própria consolidação do que havia de mais moderno no paradigma da Revolução Burguesa: os Estado/Nação; o subdesenvolvimento é um processo e como tal tem uma dinâmica, apenas atacando e destruindo sua lógica estruturante é que o processo pode mudar de rumo. Chega-se dessa forma ao problema da correta interpretação e diagnóstico do fenômeno tarefa da intelligentsia na construção de um paradigma explicativo coerente e lúcido (no caso a teoria do subdesenvolvimento); e, na seqüência, a elaboração de instrumentos capazes de corrigir essa situação. Não foram apenas os paradigmas econômicos que Furtado colocou na berlinda; foi a própria concepção civilizatória que apostava na ação individual, nos valores da competição e do egoísmo privado como motor de construção do progresso social. Há aqui uma sutil, porém feroz metamorfose - no paradigma liberal é na esfera privada que encontramos as energias capazes de realizar o progresso comum; na teoria do subdesenvolvimento 
| 82 |

Capital, trabalho e intelligentsia...

o planejamento é ferramenta lógica que desconfia dessa virtude mágica do individualismo 8 . Em seu lugar, promove como ponto de partida o sistema (como em List) e como ponto de chegada o conjunto dos interesses sociais (no jargão contemporâneo chamado de nação, conceito fácil de estabelecer correspondência semântica com o velho conceito de res publica).

A naturalidade da História, movida pela soma das transformações geradas nas ações individuais de caráter racional-contábil encontra um adversário. Na teoria do subdesenvolvimento é ainda o homem e sua racionalidade que podem transformar a dinâmica histórica, mas o eixo dessa ação não está no individuo (sede de razão e julgamento no argumento liberal) e sim na res publica representada pelo único ator capaz de espelhar o interesse comum - o Estado. Se é a vontade política aquela capaz de quebrar a inércia sistêmica da "vocação do subdesenvolvimento" (o circulo vicioso de Nurkse), se foi rompido o espontaneismo providencial do Mercado, substituído um projeto de desenvolvimento pensado, qual será a natureza desse projeto de futuro que se racionaliza na teoria e na ação do período? Ou seja, de qual desenvolvimento Furtado estava falando, uma vez que a exigência histórica do período impôs aos atores que somavam a intelligentsia da comunidade nacional um salto de consciência para analisar e ponderar sobre esse produto intelectual chamado desenvolvimento?

\footnotetext{
${ }^{8}$ No mesmo sentido das críticas formuladas por Keynes em $O$ fim do laissez faire, publicado em 1926, a racionalidade propugnada pelo liberalismo (econômica e política) não era capaz de encontrar o 'progresso das nações' entregue a força guia da mão invisível, nem as virtudes públicas a partir dos vícios privados. A liberdade individual por mais racionalizada que seja sob o primado da maximização de interesses não pode produzir a liberdade social; ao contrário, o máximo de autonomia de escolhas no mundo econômico é sinal certo de caos social. A crença nas virtudes do individualismo esboroava-se na Europa em direção ao regulacionismo keynesiano e as alternativas da socialdemocracia do Welfare State.
} 


\section{As tarefas da modernização - mudança social e a tensão capital versus trabalho}

O afastamento do ideário liberal assume na tese desenvolvimentista de Furtado uma faceta curiosa e em alguns momentos aparentemente contraditória. Em termos econômicos seu projeto desenvolvimentista recusa as premissas liberais e valoriza a regulação econômica sob dois pressupostos: 1) da irracionalidade dos agentes econômicos, em especial os empresários (equivalente do termo burguesia), que tomam decisões racionais e positivas em termos privados, mas desastrosas em termos do sistema econômico nacional por conta do aumento dos pontos de estrangulamento estrutural; e 2) na afirmação de que o ponto de mutação de uma economia subdesenvolvida incide no problema do tamanho do mercado consumidor interno e na mudança do processo e condições da produção - mutação que só pode ocorrer pelo processo de distribuição de riqueza via elevação dos salários (a proximidade com os postulados keynesianos é inequívoca). Por este ângulo, privilegiando a regulação pública da economia enquanto técnica de incentivo ao aumento e qualificação da produção (portanto na defesa dos interesses do capital) e a proteção dos salários como mola da renovação tecnológica e na sustentabilidade do desenvolvimento nacional, Furtado afasta-se dos princípios axiomáticos da autodeterminação eficiente da economia. No entanto, por outro lado, valoriza o conflito como condição indispensável para a implantação do projeto desenvolvimentista - em especial no problema da organização dos trabalhadores e a defesa da democracia, tomados não como corolário do desenvolvimento ou objeto de desejo último do processo de desenvolvimento, e sim motor ou força motriz necessária ao projeto desenvolvimentista.

São esses os aspectos que passo agora a examinar e que numa primeira abordagem trabalham com a hipótese de que a concepção sistemática da teoria furtadiana forja não apenas uma teoria econômica e/ou histórica, mas uma teoria da modernização. No desdobramento, proponho analisar a singular desconfiança de Furtado sobre as virtudes da burguesia nacional e no enfoque 
| 84 |

Capital, trabalho e intelligentsia...

contrário, valorizando o trabalho como ator fundamental para constituição de uma dinâmica de desenvolvimento autóctone e auto-sustentada.

\section{Democracia e participação - neutralizando os setores anacrônicos}

A tipologia furtadiana do subdesenvolvimento de grau-superior, formulada de maneira completa por Furtado no texto Teoria e Política do desenvolvimento econômico (1967), é o aperfeiçoamento da tese que orienta já a construção dos trabalhos anteriores (vê-se a sombra na análise feita em Formação Econômica do Brasil) e permite ajustar ao cenário brasileiro a perspectiva intelectual que vinha se fortalecendo mundialmente sobre o problema do planejamento do desenvolvimento a partir da existência das "condições de arranque" (Myrdal, 1956; Nurkse, 1957; Rostow, 1964). Da análise das condições originárias na etapa café-industrialização (modelo de substituição de importações), da brecha histórica aberta pelas crises mundiais e pela internalização momentânea do fluxo econômico (chave da interpretação em Formação), Furtado passa nos textos subseqüentes a analisar não mais as condições do subdesenvolvimento, mas os obstáculos que impediriam o salto definitivo para a autonomia da economia nacional. Este desdobramento vai apresentar as restrições econômicas que perpetuam o subdesenvolvimento como amparadas pelas condições sociais e pelas instituições políticas numa relação de mútua determinação. Este é o sentido do termo dialética utilizado pelo autor e que tomado como uso inadequado do jargão marxista sofreu severas críticas, já no período de publicação dos textos, sob a rubrica de uma concepção meramente economicista, nunca de um processo dialético ${ }^{9}$. No entanto, independente do deslocamento do termo, a pecha de economicista não calha bem ao raciocínio apresentado. Ao contrário, embora

${ }^{9}$ A crítica economicista ao uso incorreto do conceito dialética por Furtado é feita por José A. GIANNOTTI em “A propósito de uma incursão na 
a dimensão econômica tenha centralidade, a mudança social inclui outras facetas e depende da modificação das instituições políticas e de várias estruturas societárias. Não bastaria, para Furtado, mudar a situação das relações econômicas internas. Sem a destruição das estruturas anacrônicas como o poder latifundiário e senhorial, a apropriação do Estado como ferramenta de interesses particularistas, a manutenção das diferenças regionais a economia e a sociedade não poderão passar a condição de modernidade. Por outro lado, sem regulacionismo econômico, sem participação e democracia as instituições e valores da modernidade também não podem desabrochar. Como resultado, a luta pelo desenvolvimento holístico e auto-sustentado requer como condição sine qua non a mudança social, destruindo o velho e implantando o novo.

No caso da superação do subdesenvolvimento as forças anacrônicas aparecem associadas ao modelo mercantil-exportador, ao regionalismo econômico e político, condensando toda a corte de horrores do atraso. O problema da grande propriedade rural é apresentado como distorção, apresentando duas seqüelas de difícil superação: no setor mais dinâmico (setor exportação) esta estrutura é dependente do mercado internacional e tende tanto pela deterioração dos termos de troca quanto pela inevitável propensão à queda dos preços (pela condição da demanda inelástica); no setor menos dinâmico (setor voltado para o abastecimento do mercado interno) a produção agrícola apresenta baixa produtividade e pequena diversificação produtiva - características que somadas são responsáveis pela escassez e pelos altos preços dos alimentos (implicando, diretamente, no alto custo dos bens que formam a cesta básica do trabalhador e nas pressões oriundas da carestia e no efeito corrosivo da inflação).

dialética" in Revista Civilização Brasileira, ano I, no 3: julho de 1965. Em outro contexto, Cardoso e Falleto em Dependência e desenvolvimento na América Latina recusam o determinismo econômico das interpretações cepalinas e, é claro, por extensão, as teses de Celso Furtado. 
| 86 |

Capital, trabalho e intelligentsia...

Por outro lado, a permanência sem mudanças estruturais nesse setor manteria intacta a dependência dos centros externos de decisão econômica, o baixo dinamismo econômico, a incapacidade de expansão do tamanho do mercado consumidor interno, a hegemonia e controle sobre o aparata estatal e controle da opinião pública através dos "currais eleitorais". Por sua inserção histórica e pela função de resposta às necessidades do mercado internacional, o setor exportador possui uma grande capacidade de resistência e de manter intactos seus privilégios. Compreendendo sua natureza limitada, determinada pela situação de dependência e de incapacidade de superação das relações assimétricas, legitima-se a tarefa do planejamento econômico no enfraquecimento desse setor - quer pelo fortalecimento do segmento industrial, quer pelo estímulo ao surgimento da agricultura da pequena propriedade voltada para o mercado interno. Neste raciocínio fica claro que a economia mercantilexportadora é capaz de produzir riqueza reduzida e concentrada, mas é incapaz de originar uma dinâmica real que transforme o conjunto da economia e que responda à necessidade geral de mudança.

Mas se o segmento mercantil-exportador enfraqueceu economicamente isso não significa ma correlata fraqueza política. De onde, então, viria a força para enfrentá-lo? Da mudança estrutural da economia e da estratégia de confronto pela participação ativa da sociedade, no marco democrático. Tal processo entende-se como conseqüência do surto de industrialização que se surge no país pelas brechas abertas pelo interregno das duas guerras mundiais e pela crise de 29 - a partir de então a situação passou de dual para híbrida. De maneira inédita na história nacional passam a se confrontar duas forças, ancoradas em setores econômicos distintos: uma ligada ao universo da produção agrícola e outra ou universo da produção industrial; uma rural e outra urbana; uma economia interna outra economia externa. Com a redemocratização pós-45 a força das cidades e dos trabalhadores urbanos passou a se expressar nas urnas, contrabalançando pelo voto citadino a hegemonia das oligarquias 
regionais ligadas ao modelo exportador. Também no plano ideológico, a industrialização tornava-se dia a dia mais reconhecida como passaporte para solucionar os graves problemas sociais em expansão desde os anos 20. A pressão dos setores urbanos por mudanças e a existência do canal democrático permitiriam a diminuição do peso político do setor agrárioexportador, facilitando o processo de modernização.

O específico do Estado democrático de base capitalista não é propriamente uma tendência à eliminação dos privilégios. Pelo contrário, os grupos privilegiados podem nele crescer ou conservar o seu poder desde que os disputem dentro espaço dentro da arena democrática (e na mesma direção adotada por Mannheim, ao terem que debater seus projetos - utópicos ou ideológicos - os grupos realizam uma síntese política, mediada pela escolha e aceitação geral dos interesses que apareçam como mais gerais ao conjunto social). Outro dado curioso é que o projeto de desenvolvimento furtadiano inova várias percepções sobre quais, na realidade, são os problemas e a "questão social" nacional. No grande grupo dos desenvolvimentistas dos anos 50/60 o mote da industrialização era consenso ${ }^{10}$, mas as relações entre capital e trabalho, interno e externo, limites da ação do Estado (principalmente na definição de direitos sociais ou repartição da riqueza) provocam divergências extremas. Furtado vai se tornando um intelectual único nesse debate pelas proposições e valores que sustentam seu projeto de desenvolvimento. Se, como apontado anteriormente, era inédita a defesa da democracia (como finalidade e meio), ainda mais singular será a subversão sobre o Sujeito propulsor do desenvolvimento (o trabalho e não o capital), baseada na desconfiança incomum e original quanto ao papel das elites industriais (burguesia nacional) e mesmo a intelligentsia que ronda o Estado (intelectuais, políticos e policy makers).

10 Exemplo dessa heterogeneidade é descrita e analisada por Bielschowsky em Pensamento Econômico Brasileiro - O ciclo ideológico do desenvolvimentismo (1988). 
| 88 |

Capital, trabalho e intelligentsia...

\section{Conflito e desconfiança: defesa do trabalho e controle do} capital

Como parte de um projeto de modernização que toma como base de sua constituição a superação de subdesenvolvimento, a dimensão econômica e os atores que dela emergem são aspectos fundamentais a serem tomados em conta. O desenvolvimentismo aceitava como fato que a economia nacional guiada pelos automatismos do mercado não poderia superar os entraves à passagem de um capitalismo industrial e mais refinado em termos tecnológicos. Embora rompido com o liberalismo, a interpretação sobre a dinâmica do capitalismo repousava ainda, em vários dos projetos de planejamento lapidados nos anos 50, vários conceitos permaneciam intactos na base desse raciocínio: o papel transformador e civilizador do progresso econômico, o lugar privilegiado para a ação criadora ou inovadora dos empresários (estes argumentos estão presentes, por exemplo, na formulação pioneira do planejamento defendida por Roberto Simonsen no inicio dos anos 40). O mesmo ocorre para a heterogênea corrente de "desenvolvimentistas" da década de 50, que podem ser tipificados e alocados em diversas categorias como desenvolvimentistas: setor privado, setor público, nacionalistas, ortodoxos, heterodoxos, esquerda, independentes, keynesianos, entre outros critérios possíveis ${ }^{11}$. O que procuro ilustrar é que sob uma mesma e genérica rubrica inúmeros projetos, filiações e interesses se abrigaram. Como resultado, para entendermos qualquer um deles um método possível é estabelecer qual a relação adotada quanto ao posicionamento frente a uma questão central na teoria econômica - o desenvolvimento econômico origina-se no lado da oferta ou no lado da demanda? Digo isto porque o simples enunciado da aceitação da regulação do estado naquele período parece-me critério insuficiente de estratificação ideológica ou teórica: para os cepalinos a filiação é keynesiana (preponderância do fator trabalho e defesa da intervenção do

${ }^{11}$ Bielschowsky, op. cit. 
poderia ser aceita em função de uma intervenção cirúrgica justificada por uma inovação a la Schumpeter. Talvez a pergunta central a ser feita é: quais os interesses prioritários que cabe ao planejamento estatal defender? Com esta inquirição o projeto furtadiano destaca-se nitidamente dos demais: a força capaz de re-orientar as relações econômicas em direção ao desenvolvimento nascem do trabalho. É através de sua força vital de cobrança que pode ser gerada a dinâmica capaz de criar um mercado interno e estimular o capitalista à inovação tecnológica constante (deslocando a estratégia de obtenção do lucro através do baixo valor dos salários ou pela fraca competição no mercado interno). De um outro ângulo, a aceitação do papel fundamental do consumo como base do crescimento da economia nacional é acompanhada de um outro aspecto inédito - a regulação e a limitação da ação do capital.

E esta lógica é combinada. O capitalista precisa ser regulado na sua ação, pois em situação de subdesenvolvimento sua irracionalidade atinge dimensões mais dramáticas do que aquelas apontadas por Keynes. A existência de um segmento industrial nacional, originado na etapa de substituição de importações, e a necessidade de atração do capital externo, exercida pelo aumento das necessidades de consumo interno e das demandas de investimento (proporcionado pela expansão das atividades industriais e comerciais locais) provocavam uma disfunção grave no ritmo e rumo do desenvolvimento da cadeia industrial. No afã de realizarem lucro no menor prazo e custo possíveis, a indústria nacional e a estrangeira selecionavam entre as alternativas de alocação de seus recursos aquelas atividades que apresentassem a maior e mais imediata taxa de retorno. Os desvios aqui originados eram inúmeros. A opção acabava por inflacionar alguns setores e esvaziar outros, criando uma instabilidade constante na estrutura econômica. O aumento da atividade industrial, em qualquer ramo, fazia pressão sobre o setor de bens de produção, área que não sendo atendida internamente aumentava a demanda por importações (as importações 
$|90|$

Capital, trabalho e intelligentsia...

gravosas), descontrolando a balança comercial e remetendo para o exterior considerável parte do capital aqui produzido.

A alternativa de produzir nacionalmente esses bens não se realizava em função da envergadura e do longo prazo de retorno dos investimentos necessários, o que minava o interesse do capital privado. Como decorrência dessas duas conjunções o leque de alternativas que se mostravam atrativas era reduzido e acentuava a concorrência nos setores que capitalizavam a maioria dos investimentos. Ora, como a lei fundamental que rege a economia de mercado é o preço, o aumento da concorrência tende a diminuir o preço dos produtos no mercado final, reduzindo a margem de lucro. Para manterem constante sua taxa de retorno, os empresários repassam a redução para o preço dos salários, reduzindo o ganho dos trabalhadores, que, na última volta do círculo, perdem poder de compra reduzindo a demanda geral do sistema - encolhendo o tamanho do mercado e iniciando uma espiral recessiva ou de estagnação econômica.

Esta percepção, de nítida filiação keynesiana, levaria Furtado $(1962,1964)$ a defender a organização dos trabalhadores como elemento fundamental para dinamizar (retroalimentar) a economia nacional, tanto pela capacidade de expansão do tamanho do mercado consumidor interno, quanto pelo 'empurrão' à incorporação de inovações tecnológicas (em substituição à tática de redução dos salários). Desta maneira, a lógica virtuosa que deflagrara a ascensão econômica crescente nas economias avançadas poderia ser aqui implementada.

Estes dois aspectos são os que mais distinguem a contribuição de Furtado das outras correntes que defendem a industrialização brasileira como plataforma para o progresso. Para Furtado a participação dos trabalhadores forçaria o capital a se renovar constantemente, ao mesmo tempo em que a elevação dos salários (aumento do consumo) seria o motor das atividades industriais - a pressão e o conflito operário seria, portanto, benéficas ${ }^{12}$.

\footnotetext{
${ }_{12}$ Para Simonsen, ao contrário, embora os salários tivessem importância como determinante do tamanho do mercado e da demanda por bens industriais, a
} 
Resumidamente, a questão do conflito é valorizada por Furtado em três direções: é o pilar da mudança social (o princípio contraditório, definido pelo autor como dialético); é a ferramenta que mina o poder dos setores atrasados que emperram o processo de modernização; e, por último, é parte essencial na produção da lógica de inovação tecnológica que alimenta o ciclo da prosperidade e do desenvolvimento econômico.

Por outro lado, cabe ao Estado através das políticas econômicas disciplinar o consumo pessoal do capitalista e a lógica decisória do investimento - corrigida e orientada através de instrumentos como tributação, políticas cambiais e creditícias, por intervenção econômica direta com a criação das estatais nos setores estratégicos e de infra-estrutura, com a política de subsídios e investimentos alocados aos setores privados mais necessários e, por último, através de mecanismos políticos de proteção do trabalho para que neste movimento se redistribua efetivamente os ganhos do progresso técnico capaz de alavancar e expandir o mercado consumidor interno.

Como outra face desse processo Furtado indica a necessidade de fiscalização também da ação do Estado. Afinal os problemas de deturpação do projeto de desenvolvimento nascem de inúmeras fontes. Da história pregressa, pela capacidade de apropriação por parte dos setores anacrônicos do controle do Estado e dos recursos públicos. Da pressão internacional que após o fim da Segunda Guerra restabelece a ordem internacional que procura manter através do comércio internacional uma divisão do trabalho que preserve os interesses das economias centrais. Da moderna economia nacional pela sua inclinação imediatista do lucro fácil e que nesse processo coloca em risco

origem do ciclo virtuoso estava na implementação da produção ("crescer primeiro, distribuir depois"); além da visão catastrófica de Simonsen sobre o papel destrutivo do antagonismo entre as classes - leitmotif de sua análise sobre a necessidade de distribuição dos frutos do progresso entre todos os agentes da produção (Cepêda, 2004). 
| 92 |

Capital, trabalho e intelligentsia...

seu próprio processo de acumulação cria um estrangulamento da potência latente do mercado interno e aumenta a pressão inflacionária dos gargalos estruturais. Do lado dos planejadores sua incapacidade de serem os portadores da síntese, os operadores da metamorfose capaz de defender e implementar o interesse público - por erro ou dolo, tanto faz. O problema da mentalidade ou estilo de pensamento que rege o hibridismo das formações subdesenvolvidas só pode ser superado pela mudança orientada, pelo planejamento que incide em duas vertentes: instituições econômicas e políticas, e mudança de valores pela vitalização da opinião pública e pela reforma educacional - itens lapidares da teoria desenvolvida por Mannheim (1962 A, 1962 B, 1972) - e que implica na convergência não somente de método, mas também de visão de mundo compartilhada entre o sociólogo alemão e o intelectual brasileiro.

Como a elaboração teórica tem também como função organizar o campo político, nesta batalha mista de objetividade científica (diagnóstico) e escolhas políticas (poderosos projetos já que filhos da racionalização) o peso e o papel da intelligentsia são enormes. Uma mesma questão passa a ser de capital importância: como impedir que este conhecimento, munido da ferramenta do planejamento não se transforme em instrumento de opressão e de desvio? Vinculando-o de um lado ao paradigma republicano e do outro levando a capacidade de controle por parte da sociedade pela via democrática (na verdade os dois aspectos pertencem a uma lógica única: o projeto republicano da polis moderna é o da combinação entre sociedade e Estado, entre indivíduo e cidadão, entre razão e política ${ }^{13}$ ). Desse cenário, de novo a dimensão política é resgatada como central no projeto furtadiano através da defesa da democracia. Apenas o controle social pode mudar a lógica do

\footnotetext{
13 Perspectiva na qual o procedimento político por pertencer ao domínio do que é de todos deveria balizar-se pela ação racional - análise dos dados, reflexão, ponderação e escolhas efetuadas por critérios que aliem o particular ao geral (como no dilema dissecado pela filosofia política kantiana). Por ser o 'espaço da deliberação e do futuro' (contingência) isso não significa que a política seja a dimensão do caos.
} 
subdesenvolvimento cobrando do Estado um destino público para o crescimento econômico.

Das teorias que emergiram nos anos 50/60, a proposta de Furtado é a única na qual o cruzamento entre política e economia não assume um caráter meramente instrumental. Ao contrário, a democracia e a organização dos diversos atores sociais é parte estrutural do desenvolvimento econômico e do sonho do desenvolvimento nacional. Valores como participação, democracia, racionalidade e disputa (tão ausentes da maioria da produção intelectual nacional) são incorporados e utilizados como elementos que combinam, de fato, a modernização econômica com a modernização social e implicam numa aposta de projeto de futuro mais humano e com justiça social.

\section{Bibliografia}

BIELSCHOWSKY, Ricardo. Pensamento Econômico Brasileiro. Rio de Janeiro: IPEA: INPES, 1988.

BRESSER-PEREIRA, Luiz Carlos. Subdesenvolvimento e desenvolvimento. Rio de Janeiro: Zahar, 1969.

- Desenvolvimento e Crise no Brasil (1930-1967). Rio de Janeiro: Zahar, 1968.

BRESSER-PEREIRA, Luiz Carlos; REGO, José Márcio (org.). A grande esperança em Celso Furtado. São Paulo: Contraponto, 2001.

CAMARGO, Aspásia Camargo; LOYOLA, Maria A.. Pensamento Contemporâneo: Celso Furtado. Rio de Janeiro: UERJ, 2002.

CEPÊDA, Vera Alves. Raízes do pensamento político de Celso Furtado - desenvolvimento, nacionalidade e Estado democrático. São Paulo: FFLCH/ USP. Dissertação de mestrado, 1998.

. Roberto Simonsen e a formação da ideologia industrialista no Brasil: limites e impasses. 346 f. 2004. Tese (Doutorado em Ciência Política) - Faculdade de Filosofia, Letras e Ciências Humanas, Universidade de São Paulo, São Paulo, 2004.

FURTADO, Celso. A Economia Brasileira. Rio de Janeiro: A Noite, 1954. 
| 94 |

Capital, trabalho e intelligentsia...

Perspectiva da Economia Brasileira. Rio de Janeiro: DASP, 1958.

Operação Nordeste. Rio de Janeiro: ISEB, 1959.

A Pré Revolução Brasileira. 2ª edição. Rio de Janeiro: Fundo de Cultura, 1962.

Dialética do Desenvolvimento. Rio de Janeiro: Fundo de Cultura, 1964.

. Desenvolvimento e Subdesenvolvimento. $3^{\text {a }}$ edição. Rio de Janeiro: Fundo de Cultura, 1965.

Um Projeto para o Brasil. Rio e Janeiro: Saga, 1968.

Teoria e Política do Desenvolvimento Econômico. $4^{\mathrm{a}}$ edição.

São Paulo: Editora Nacional, 1971.

- O Mito do Desenvolvimento Econômico. Rio de Janeiro: Paz e Terra, 1974.

Análise do 'Modelo' Brasileiro. Rio de Janeiro: Civilização Brasileira, 1975.

- A Fantasia Organizada. 5a edição, Rio de Janeiro: Paz e Terra, 1985.

- A Fantasia Desfeita. Rio de Janeiro: Paz e Terra, 1989.

- Os Ares do Mundo. Rio de Janeiro: Paz e Terra, 1991.

. Formação Econômica do Brasil. 23ª edição, São Paulo: Editora

Nacional, 1995.

Obra Autobiográfica. Rio de Janeiro: Paz e Terra, 1997.

LIPSET, Seymour Martin. O Homem Político. Rio de Janeiro: Zahar Editores, 1967.

MALLORQUIN, Carlos. Celso Furtado: um retrato intelectual. São Paulo: Contraponto, 2005.

MANNHEIM, Karl. Ideologia e utopia. $3^{\text {a }}$ edição. Rio de Janeiro: Zahar, 1968.

Sociologia do conhecimento. Porto: Rés, (s/d).

. Sociologia Sistemática. São Paulo: Pioneira, 1962. (A)

Homem e a sociedade. Rio de Janeiro: Zahar, 1962. (B)

MYRDAL, Gunnar. Teoria Econômica e Regiões Subdesenvolvidas. 3 à edição, Rio de Janeiro: Saga, 1972.

NURKSE, Ragnar. Problemas de formação de capital em países subdesenvolvidos. Rio de Janeiro: Civilização Brasileira, 1957. 
OLIVEIRA, Francisco de. Celso Furtado. (Coleção Grandes Cientistas Sociais). São Paulo; Ed. Ática, 1983.

A navegação venturosa. São Paulo: Boitempo, 2003.

ROSTOW, W.W. Etapas do Desenvolvimento Econômico. 2ª edição. Rio de Janeiro: Zahar, 1964. 